\title{
In vitro Investigation of Mucuna pruriens Seed Extracts to Treat Erectile Dysfunction
}

\author{
Natthachai Duangnin, Thanyaluck Phitak, \\ Peraphan Pothacharoen, and Prachya Kongtawelert*
}

Thailand Excellence Center for Tissue Engineering and Stem Cells, Chiang Mai University, Chiang Mai 50200, Thailand

*Corresponding author. E-mail: prachya.kongtawelert@gmail.com

https://doi.org/10.12982/CMUJNS.2018.0011

\begin{abstract}
M. pruriens seeds are a natural product with health benefits, including treating erectile dysfunction (ED). However, the active compounds and their mechanisms of action are unclear. In this study, we used polarity gradient extraction to isolate four fractions from the crude extract of $M$. pruriens seeds using hexane, EtOAc, BuOH, and water. All fractions were used to treat three cell lines: C6, Ea.hy926, and HCT-15. The water fraction significantly promoted nitric oxide (NO) production in C6 cells via neuronal nitric oxide synathase (nNOS) gene upregulation. M. pruriens fractions with high polarity promoted NO production in Ea.hy926 through the upregulation of endothelial NOS (eNOS) and inducible NOS (iNOS) genes. The $\mathrm{BuOH}$ and water fractions of M. pruriens extract were involved with cyclic GMP specific-phosphodiesterase (PDE5) and iNOS gene upregulation in HCT-15, which might result in maintenance of intracellular cGMP. According to the NIST library, 2,4-bis(1,1-dimethylethyl)-phenol, a phytochemical, may play a role in nNOS upregulation; this was only found in the water fraction. Protocatechuic acid, methyl ester, and $\gamma$-sitosterol were also found in the high-polar fractions of M. pruriens extract and might be involved with eNOS gene upregulation. The ability of M. pruriens extract to provoke NO production in neurons indicated the potential for using M. pruriens seeds as an alternative medicine for erectile dysfunction therapy.
\end{abstract}

Keywords: Mucuna pruriens, Erectile dysfunction, Nitric oxide, GC/MS

\section{INTRODUCTION}

Erectile dysfunction (ED), or the failure to achieve or maintain sufficient penile erection for sexual intercourse (NIH, 1993), is one of the most common forms of deteriorating organ function among aging men (Prins et al., 2002). The trigger includes impaired function of vascular arteries and the smooth muscles or neurons within the penile tissues (Dean and Lue, 2005; Gratzke et al., 2010). In the cellular mechanism of a penile erection, nitric oxide (NO), which is produced by endothelial cells and neurons, plays an important role in cellular stimulation through activation via the NO/cGMP pathway; but NO is reduced in ED 
(Burnett, 2002). Current ED therapeutic guidelines suggest maintaining intracellular cyclic GMP (cGMP) using a cGMP-specific phosphodiesterase (PDE5) inhibitor, such as sildenafil $\left(\right.$ Viagra $\left.^{\circledR}\right)$ (Andersson, 2011). However, sildenafil has serious, even life-threatening, side effects, including severe hypotension and cardiac arrhythmia (Chamsi-Pasha, 2001). Effective and safer treatment options for ED therapy are still required.

Mucuna pruriens, or the velvet bean, is a tropical plant that has been described in ancient Ayurvedic literature as a medically beneficial plant (Kavitha and Thangamani, 2014). Its seed is rich in levodopa (L-DOPA), and has been used to treat Parkinson's disease (Pulikkalpura et al., 2015). The extract of $M$. pruriens seeds have also been shown to reduce serum glucose levels in diabetic rats (Majekodunmi et al., 2011). Its seed extracts have also been shown to improve sexual behavior in rats with both normal and diabetic-induced ED (Suresh et al., 2009; Suresh and Prakash, 2012). Ketkar et al. (2011) attributed this effect to L-DOPA in the seed extract. However, Both et al. (2005) showed that while L-DOPA increased sexual appetite, it was not involved with the genital organs or sexual arousal. The seeds of $M$. pruriens have been reported to contain a number of phytochemicals, including alkaloids, phenolic compounds, and saponins (Adebowale et al., 2005). Some of these natural substances are reported to possess various biological activities that might be useful for treating ED.

This study used polarity gradient extraction to extract the phytochemicals in $M$. pruriens seeds and then conducted an in vitro investigation of their possible role in treating erectile dysfunction.

\section{MATERIALS AND METHODS}

\section{Materials}

Sildenafil citrate $\left(\right.$ Viagra $\left.^{\circledR}\right) 100 \mathrm{mg}$ tablets were purchased from Pfizer (Thailand) Ltd. Griess's reagent and 2,2-Diphenyl-1-picrylhydrazyl (DPPH) were obtained from SigmaAldrich $^{\circledR}$ Inc., Singapore. cGMP Parameter Assay Kit was purchased from R\&D Systems, Inc., USA. Illustra RNAspin Mini RNA Isolation Kit was purchased from GE Medical Systems (Thailand) Ltd. Tetro cDNA Synthesis Kit and SensiFAST ${ }^{\mathrm{TM}} \mathrm{SYBR}^{\circledR}$ Lo-ROX Kit were purchased from Bioline Singapore. Reagents used in cell culturing were acquired from Gibco $^{\circledR}$, Thermo Fisher Scientific Co., Ltd., Thailand. All chemicals used in this study were of analytical grade.

\section{M. pruriens seed extract preparation}

M. pruriens seeds were harvested from Mae Taeng District, Chiang Mai Province, Thailand between March and May, 2014. The M. pruriens plants used in this study were deposited at the herbarium at the Faculty of Pharmacy, Chiang Mai University (voucher number 023155). The seed pods and hairs were completely removed from the specimens. The seeds were then washed thoroughly with tap water and dried at $60^{\circ} \mathrm{C}$ overnight, after which they were blended into a fine powder using an industrial blending machine. One kilogram of powder was macerated with $4 \mathrm{~L}$ of methanol at room temperature for seven days with occasional stirring. The methanolic solution was filtered with Whatman's No.1 filter membrane and evaporated using a vacuum evaporator. The extraction was repeated four times and all the extracts were pooled. An appropriate amount of warm distilled water was used 
to reconstitute the extract. Diethyl ether in a volume equal to the distilled water was used to eliminate excess fatty matter. The water layer was collected and evaporated to eliminate any remaining organic solvent and the residue was dried using lyophilization. The extract from the water layer was designated as the 'crude fraction'. The crude fraction was then reconstituted with an appropriate amount of distilled water and transferred to a separating funnel.

We used polarity gradient extraction to segregate the constituent phytochemicals based on their polarities (Sasidharan et al., 2011), usng hexane, ethyl acetate, and butanol in a volume equal to the dissolved distilled water. Each solvent was used to extract the crude fraction for three rounds. Each fraction was pooled and the solvent eliminated using a rotary evaporator.

The antioxidant activity of each fraction was determined using DPPH assay as previously described (Jing et al., 2012). Briefly, the solution of M. pruriens fractions was mixed with DPPH solution for 24 hours and the absorbance was measured at $515 \mathrm{~nm}$.

\section{Phytochemical identification using GC/MS}

All $M$. pruriens seed extracts were dissolved in methanol to produce a $1 \mathrm{mg} / \mathrm{ml}$ solution. One $\mu \mathrm{l}$ of each sample was injected in a splitless mode into a GC-FID apparatus (GC 7890A Agilent Technology) attached to a MS instrument (MSD 5975C (EI) Agilent Technology) located at the $1^{\text {st }}$ Regional Medical Sciences Center, Chiang Mai, Thailand. The chromatographic system was operated according to Karunanithi et al. (2012). All peaks were identified using the MS spectra library provided with the Agilent GC/MS software.

\section{Cell culturing and treatment}

This study used three cell lines, representing the cells of interest: rat glioma cell line C6 (ATCC ${ }^{\circledR}$ number CCL-107), to represent neuronal cells; human endothelial hybrid cell line Ea.hy926 (ATCC ${ }^{\circledR}$ number CRL-2922) substituting for endothelial cells; and human colorectal carcinoma cell line HCT-15 (ATCC ${ }^{\circledR}$ number CCL-225), where PDE5 is highly expressed, and which has been studied in relation Sildenafil (Mei et al., 2015). Ea.hy926 was cultured in Dulbecco's Modified Eagle Medium (DMEM) complemented with 10\% fetal bovine serum, 2\% HAT medium, $100 \mathrm{U} / \mathrm{ml}$ penicillin G sodium, and $100 \mu \mathrm{g} / \mathrm{ml}$ streptomycin. C6 and HCT15 were cultured in RPMI 1640 medium using the complements similar to Ea.hy926, but without the HAT medium. The cells were stored in an incubator with $5 \% \mathrm{CO}_{2}$ at $37^{\circ} \mathrm{C}$; the experiments were not conducted until their densities reached $80 \%$ confluence in a 6 -well plate. Phytochemicals at indicated concentrations from the MTT assay were used to treat the cells. Sildenafil, at a concentration of $25 \mu \mathrm{M}$, was used as the positive control. After treating for 24 hours, cell lysates were collected to determine gene expression and intracellular cGMP levels; culture supernatants were collected and NO measured.

\section{MTT assay}

The appropriate doses of the $M$. pruriens extracts were determined by MTT assay. The M. pruriens extracts, at concentrations of $1-1,000 \mu \mathrm{g} / \mathrm{ml}$, were used to treat each cell line for 24 hours, after which the culture supernatants were removed. Cells were washed twice by $1 \mathrm{x}$ PBS. MTT dye was added and the cells incubated for a further four hours before removing the MTT-containing media. DMSO was added and the absorbance was measured at $540 \mathrm{~nm}$. The extract concentrations at which the cell survival rate exceeded $80 \%$ was considered appropriate. 


\section{Nitric oxide determination}

After treatment, $1 \mathrm{ml}$ of culture supernatant was immediately collected and mixed with Griess's reagent $(0.1 \% N$-(1-naphthyl) ethylenediamine dihydrochloride, $1 \%$ sulfanilamide, and $2.5 \% \mathrm{H}_{3} \mathrm{PO}_{4}$ ) in an equal volume. The mixture was incubated at room temperature for 10 minutes and then measured at an absorbance of $540 \mathrm{~nm}$ using a microplate reader. At varying concentrations of sodium nitrite $(1-100 \mu \mathrm{M})$, the stable form of NO in the samples was measured to generate a standard curve (Bryan and Grisham, 2007).

\section{Intracellular cGMP determination}

A Parameter ${ }^{\mathrm{TM}}$ cGMP Competitive ELISA Kit was used to determine intracellular cGMP levels. The treated HCT-15 cells were lysed using the lysis buffer provided with the test kit and $100 \mu \mathrm{l}$ of each sample was applied to the analytical plate. ELISA followed the manufacturer's guidelines. After ELISA, absorbance was measured at UV $450 \mathrm{~nm}$. The concentration value of cGMP in the samples was measured and compared to the standard curve generated from standard cGMP at a concentration range of $0-500 \mathrm{pmol} / \mathrm{ml}$ using 4-parameterlogistics compatible software.

\section{Gene expression analysis using real-time reverse transcriptase polymerase chain reaction (real-time RT PCR)}

Total RNA was extracted from the treated cells using an Illustra RNAspin Mini RNA Isolation Kit. The extracted RNA $(1.0 \mu \mathrm{g})$ was used as a template to synthesize cDNA using a Tetro cDNA Synthesis Kit. Real-time RT-PCR was performed using a SensiFAST ${ }^{\mathrm{TM}}$ $\mathrm{SYBR}^{\circledR}$ Lo-ROX Kit, following the manufacturer's manual. PCR primers were obtained from InvitrogenTM. The reactions were operated on a 7,500 Fast Real-Time PCR instrument. The data were collected and the fold changes in the gene expression were calculated using the $2^{-\triangle \triangle C T}$ method (Schefe et al., 2006). iNOS, eNOS, and PDE5 were the genes of interest in human cells; the murine genes in this study were iNOS and nNOS. $\beta$-actin of both species was used as the reference constitutive gene. We used the following primer sequences:

Homo sapiens nitric oxide synthase 2 (NOS2):

Forward 5'-CTGCTTGAGGTGGGCGG-3'

Reverse 5'-GTGACTCTGACTCGGGACGCC-3'

Homo sapiens nitric oxide synthase 3 (NOS3):

Forward 5'-TGGACCTGGATACCCGGAC-3'

Reverse 5'-TGGTGACTTTGGCTAGCTGG-3'

Homo sapiens phosphodiesterase 5A (PDE5A):

Forward 5'-GAAAAGGACTTTGCTGCTT-3'

Reverse 5'-TGATTTTGTTTGCATCATGT-3'

Homo sapiens actin beta (ACTB):

Forward 5'-CGTGAAAAGATGACCCAGATCA-3'

Reverse 5'-CACAGCCTGGATGGCTACGT-3'

Rattus norvegicus nitric oxide synthase 1 (NOS1):

Forward 5'-ACTGACACCCTGCACCTGAAGA-3'

Reverse 5'-GTGCGGACATCTTCTGACTTCC-3' 
Rattus norvegicus nitric oxide synthase 2 (NOS2):

Forward 5'-CAGCTGGGCTGTACAAACCTT-3'

Reverse 5'-CATTGGAAGTGAAGCGGTTCG-3'

Rattus norvegicus actin, beta (Actb):

Forward 5'-TTCAACACCCCAGCCATGT-3'

Reverse 5'-TGGTACGACCAGAGGCATACAG-3'

\section{Statistical analysis}

The statistically significant differences between the groups were determined using one-way ANOVA test. All results are displayed as mean \pm SEM of triplicate independent experiments. Statistical significance was assumed at $p<0.05$.

\section{RESULTS}

\section{Qualitative analysis of $M$. pruriens seed extract}

The extraction process with methanol produced $106.46 \mathrm{~g}$ of methanolic extract (10.65 $\% \mathrm{w} / \mathrm{w})$. The extract was then defatted using diethyl ether; $36.31 \mathrm{~g}$ of fatty matter was eliminated $(3.63 \% \mathrm{w} / \mathrm{w})$. The remaining fraction $(70.22 \mathrm{~g})$ was designated as the crude fraction $(7.02 \%$ $\mathrm{w} / \mathrm{w}$ ) and used as the source for polarity gradient extraction. The polarity gradient extraction of the hexane, EtOAC, BuOH, and water fractions yielded 13.38, 12.34, 14.26, and $28.61 \mathrm{~g}$, respectively $(1.34,1.23,1.43$, and $2.86 \% \mathrm{w} / \mathrm{w}$, respectively).

The phytochemical components of each fraction were determined using GC/MS (Figure 1). Table 1 shows the GC peaks that matched data from the MS spectra library, with probability percentages and their peak responses. From the MS spectra library, polar substances appear in the first portion of the chromatograms and nonpolar substances in the second. Interestingly, we did not find L-DOPA in any of the fractions in this study, despite previous reports that it is a major component of $M$. pruriens seeds and correspondingly should be found in the lipophilic fractions.

All peaks that could be identified by the MS spectra database were contained in the crude fraction (Figure 1A). Fatty acids and lipid derivatives, including n-Hexadecanoic acid [6], 9,12-Octadecadienoic acid (Z,Z)-, methyl ester [7], Octadecanoic acid [8], Glycerol 1-palmitate [9], and Octadecanoic acid, 2-hydroxy-1-(hydroxymethyl)ethyl ester [11] were found in all fractions in differing amounts. $\gamma$-sitosterol [10] was the only lipid derivative found in $\mathrm{BuOH}$ and the water fraction. The only hydrophilic component found in all fractions was 7,9-di-tert-butyl-1-oxaspiro(4,5)deca-6,9-diene-2,8-dione [5]. The phytochemical diethyl phthalate [3] was found in all fractions, although it was most clearly observed in the hexane and EtOAc fractions (Figures 1B and 1C). Sucrose [1] and protocatechuic acid, methylester [4] were found in small amounts in the $\mathrm{BuOH}$ fraction, as well the water fraction (Figures $1 \mathrm{D}$ and 1E). The phytochemical 2,4-bis(1,1-dimethylethyl)-phenol [2] was found only in the water fraction (Figure 1E). 

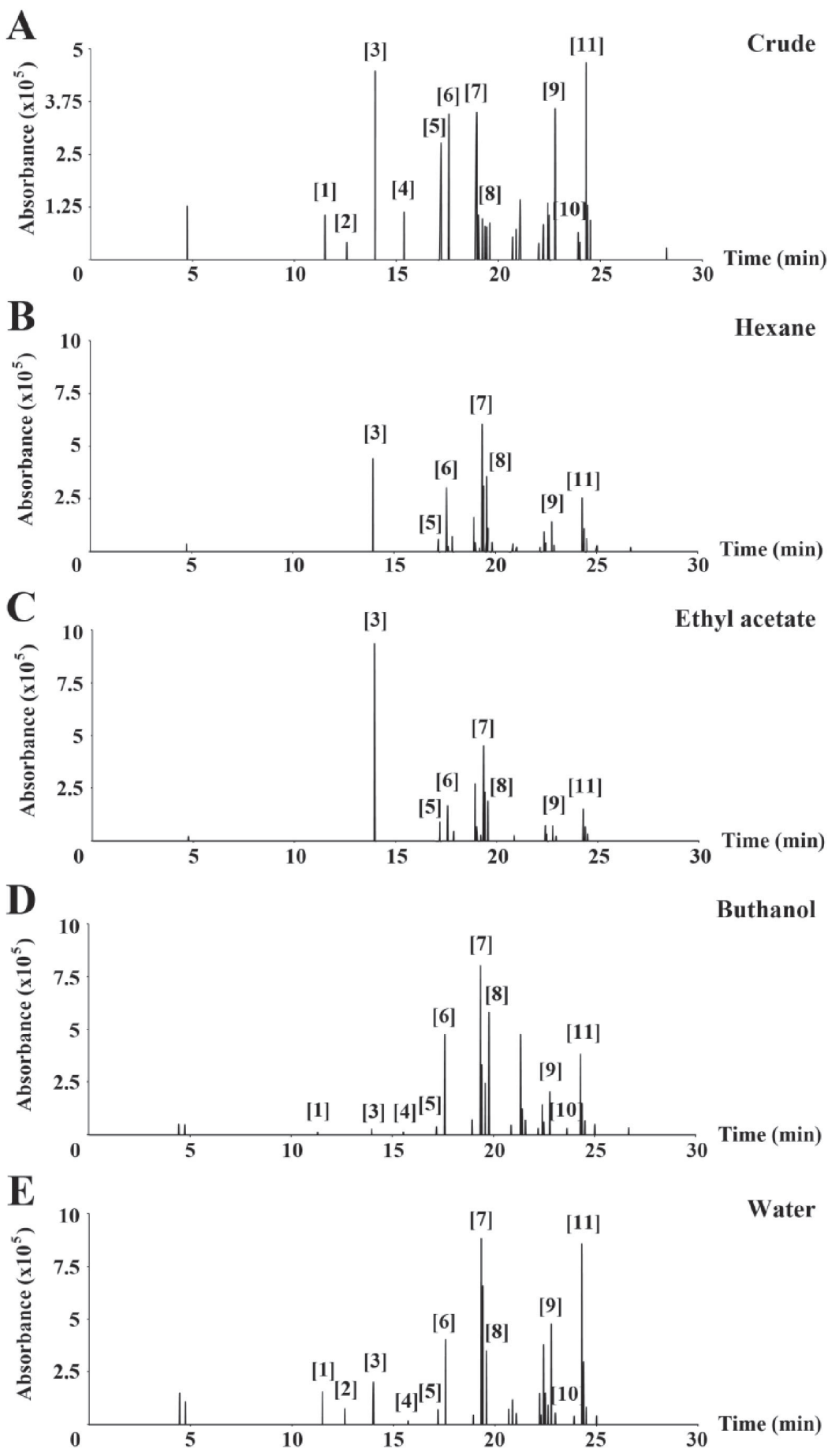

Figure 1. GC chromatogram of all fractions of M. pruriens seed extracts: crude (A), hexane (B), ethyl acetate (C), butanol (D), and water (E).

Note: The major peaks are identified in Table 1. 
Table 1. Identification of GC peaks in the chromatograms of fractions by MS spectra library.

\begin{tabular}{|c|c|c|c|c|c|c|c|c|}
\hline \multirow{2}{*}{ No. } & \multirow{2}{*}{$\begin{array}{l}\text { Retention } \\
\text { time }\end{array}$} & \multirow{2}{*}{ Phytochemical } & \multirow{2}{*}{$\begin{array}{c}\text { Probability } \\
(\%)\end{array}$} & \multicolumn{5}{|c|}{ Correlated peak area $\left(\mathrm{Abs}^{*} \mathrm{~s}\right)$} \\
\hline & & & & Crude & Hexane & EtOAc & $\mathrm{BuOH}$ & Water \\
\hline 1 & 11.49 & Sucrose & 66.8 & 305310 & 0 & 0 & 76240 & 426230 \\
\hline 2 & 12.58 & 2,4-bis(1,1-dimethylethyl)-phenol & 95.0 & 207960 & 0 & 0 & 0 & 267560 \\
\hline 3 & 13.96 & Diethyl Phthalate & 60.5 & 2038150 & 2440290 & 4141300 & 105810 & 506070 \\
\hline 4 & 15.57 & Protocatechuic acid, methy ester & 91.2 & 375030 & 0 & 0 & 97320 & 122200 \\
\hline 5 & 17.18 & 7,9-Di-tert-butyl-1-oxaspiro(4,5)deca-6,9-diene-2,8-dione & 99.0 & 1452130 & 345140 & 409750 & 336670 & 468040 \\
\hline 6 & 17.58 & n-Hexadecanoic acid & 98.0 & 1575880 & 1402450 & 1194820 & 1924120 & 1644250 \\
\hline 7 & 18.93 & 9,12-Octadecadienoic acid (Z,Z)-, methyl ester & 95.0 & 1541460 & 1866970 & 1429560 & 2059000 & 3271010 \\
\hline 8 & 19.42 & Octadecanoic acid & 97.4 & 321650 & 751050 & 597940 & 1479720 & 1032290 \\
\hline 9 & 22.48 & Glycerol 1-palmitate & 85.5 & 1577260 & 425180 & 329800 & 571500 & 1145290 \\
\hline 10 & 23.90 & $\gamma$-sitosterol & 71.0 & 392140 & 0 & 0 & 100560 & 102670 \\
\hline 11 & 24.51 & Octadecanoic acid, 2-hydroxy-1-(hydroxymethyl)ethyl ester & 91.0 & 2058280 & 658080 & 526060 & 1204780 & 2828030 \\
\hline
\end{tabular}

Note: Probability percentages were measured by comparing to the MS spectra in the NIST library. Peak responses of each fraction are displayed as the correlated peak area.

\section{Antioxidant properties of $M$. pruriens fractions}

The antioxidant activities of each fraction were related to the components found in the GC chromatogram (Figure 2). The fractions with high polarity displayed higher antioxidant activity than the low polarity fractions. The water fraction showed the best antioxidant activity among the $M$. pruriens fractions.

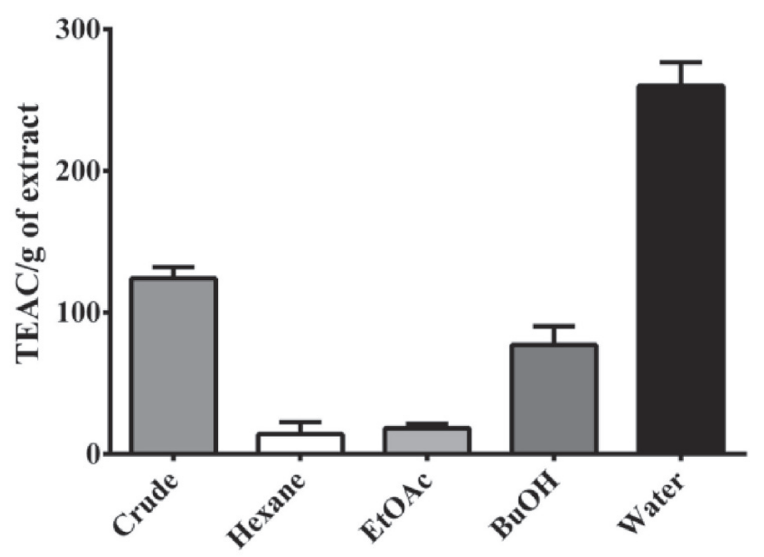

Figure 2. Antioxidant properties of M. pruriens seed fractions as measured by DPPH assay. Antioxidant properties, or Trolox equivalent antioxidant capability (TEAC), are in Trolox Equivalents (TE) per gram of dry weight of extract. 


\section{Cytotoxicity of $M$. pruriens fractions}

Prior to the in vitro experiments, we determined the appropriate concentration of the M. pruriens fractions to apply to the tested cell lines using the MTT assay. The MTT results revealed that at concentrations higher than $125 \mu \mathrm{g} / \mathrm{ml}$ (Figures $3 \mathrm{~A}$ to $3 \mathrm{C}$ ), cell survival rates in each experimental group were less than $80 \%$. At concentrations of less than $62.5 \mu \mathrm{g} / \mathrm{ml}$, cell viability exceeded $80 \%$; we thus selected a concentration of $50 \mu \mathrm{g} / \mathrm{ml}$ for all M. pruriens fraction for further study. The toxicity of the extracts did not involve the DMSO, which was used at a concentration of $0.05 \% \mathrm{v} / \mathrm{v}$ in the culture medium to dissolve the fractions. $\mathrm{The} \mathrm{IC}_{50}$ values from the cytotoxicity tests of each fraction are displayed in Table 2.
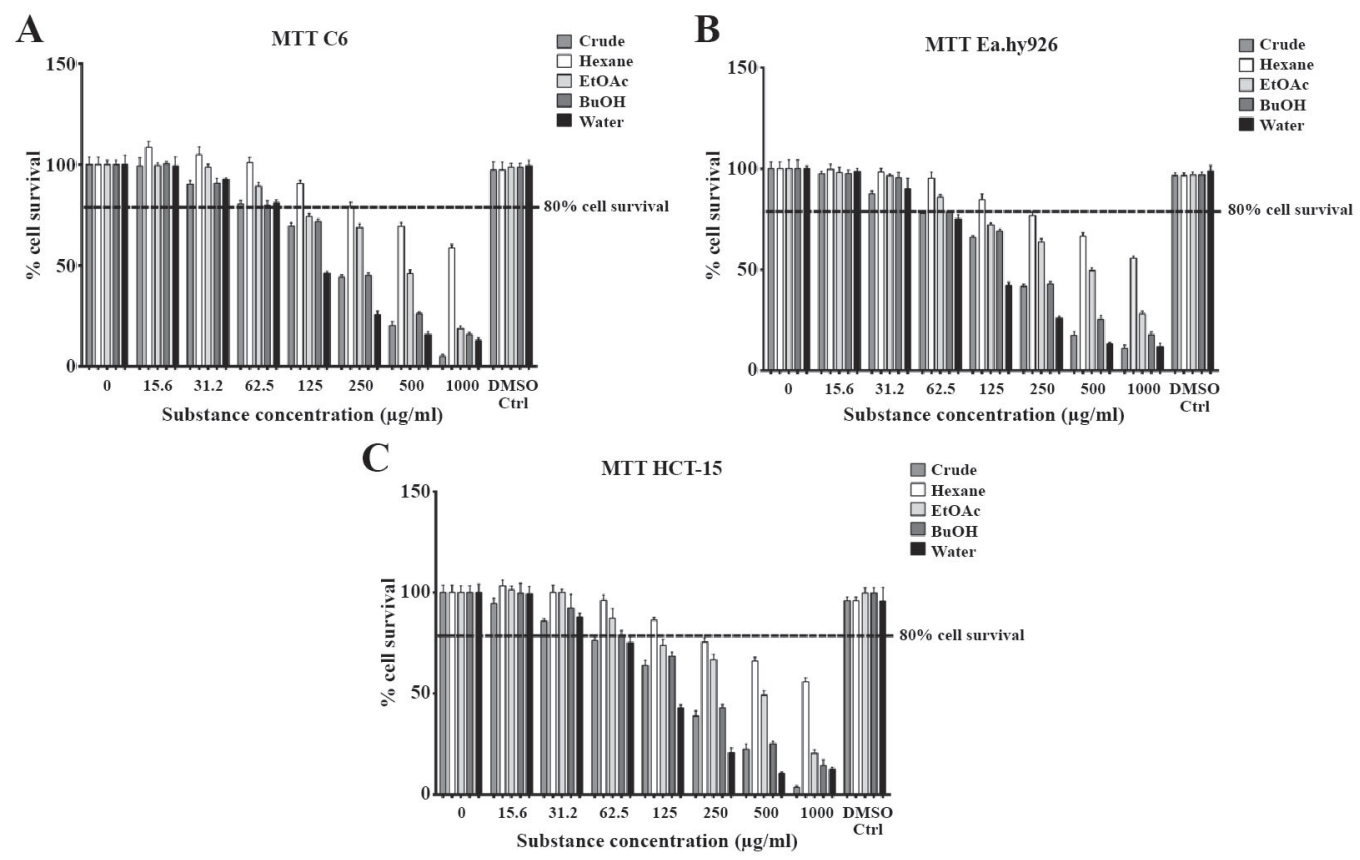

Figure 3. Cytotoxicity of cell lines used in this study (A) C6, (B) Ea.hy926, and (C) HCT-15. At concentration of $62.5 \mu \mathrm{g} / \mathrm{ml}$ or less, survival rates exceeded $80 \%$ in all fractions, so the concentration of $50 \mu \mathrm{g} / \mathrm{ml}$ was chosen for further studies.

Table 2. $\mathrm{IC}_{50}$ value of $M$. pruriens fractions on cell lines.

\begin{tabular}{lccccc}
\hline \multirow{2}{*}{ Type of cell line } & \multicolumn{5}{c}{ IC $_{\mathbf{5 0}}(\boldsymbol{\mu g} / \mathbf{m l})$} \\
\cline { 2 - 6 } & Crude & Hexane & EtOAc & BuOH & Water \\
\hline C6 & $247.6 \pm 2.5$ & $>1000$ & $450.2 \pm 6.9$ & $234.3 \pm 3.4$ & $86.7 \pm 2.7$ \\
Ea.hy926 & $258.4 \pm 3.0$ & $>1000$ & $506.6 \pm 4.7$ & $239.1 \pm 2.6$ & $94.6 \pm 1.5$ \\
HCT-15 & $248.7 \pm 6.2$ & $>1000$ & $496.5 \pm 9.8$ & $245.9 \pm 3.8$ & $96.7 \pm 2.8$ \\
\hline
\end{tabular}




\section{In vitro effect of $M$. pruriens fractions on penile erection related gene expression and biomolecules}

We simulated, in vitro, the cellular situation of a penile erection and determined the effects of $M$. pruriens fractions on NOS and PDE5 gene expression, NO synthesis, and intracellular cGMP remaining in the cells using three cell lines (C6, Ea.hy926, and HCT-15), compared to $25 \mu \mathrm{M}$ Sildenafil as the positive control.

After 24 hours of treatment, Sildenafil significantly stimulated the production of NO in C6 cells (Figures 4C). However, Sildenafil did not promote the upregulation of the nNOS gene (Figure 4A), and only slightly increased iNOS gene expression (Figure 4B). The crude fractions of $M$. pruriens showed more potential for stimulating NO in C6 cells than the Sildenafil (Figure 4C). The increase in the water fraction was significant compared to both the control and Sildenafil-treated groups. The incremental increase in NO was related to the polarity of the substances. Interestingly, the water fraction of the M. pruriens seed extract was the only fraction that significantly upregulated nNOS and iNOS gene expression in C6 cells (Figures 4A and 4B).
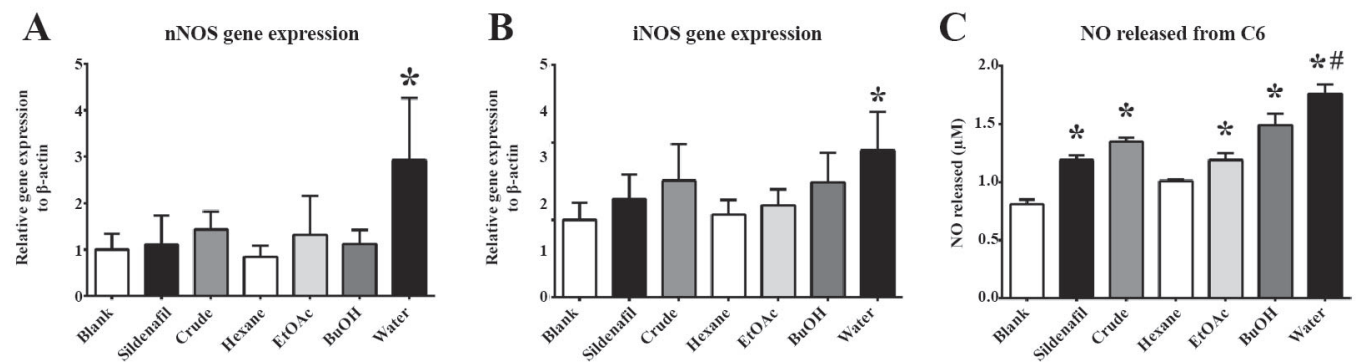

Figure 4. The in vitro effect of $M$. pruriens fractions on C6 cells: (A) nNOS gene expression, (B) iNOS gene expression, and (C) released NO level.

Note: The statistical significance of the differences between groups was determined using one-way ANOVA test. Statistical significance is assumed at $P<0.05$; * when compared to the control group, and \# when compared to the Sildenafil-treated group.

In the Ea.hy926 cell line, Sildenafil significantly promoted NO production (Figure 5C) through upregulating the eNOS and iNOS genes (Figures 5A and 5B). The crude extract of $M$. pruriens significantly promoted the release of NO in the Ea.hy926 cell line (Figure 5C), and related to the upregulation of the eNOS gene (Figure 5A). This potency was associated with the polar compounds in the $M$. pruriens extract, as the upregulation of eNOS expression gradually increased as the extract was treated with higher polar fractions. However, its potential was not comparable to that of Sildenafil. Phytochemicals contained in the EtOAC, $\mathrm{BuOH}$, and water fractions affected the upregulation of the iNOS gene in Ea.hy926 cells (Figure 5B). The water fraction of the $M$. pruriens extract significantly enhanced iNOS gene expression compared to both the control and the Sildenafil-treated groups. 
A

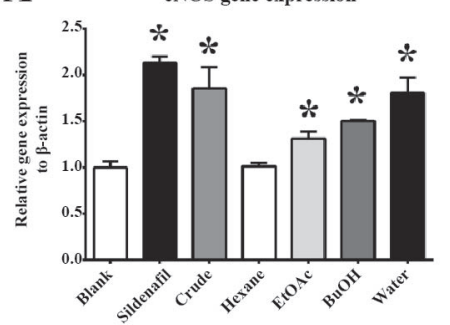

B

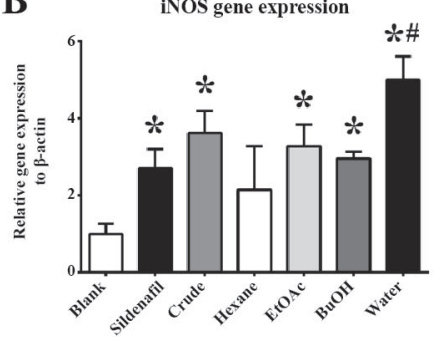

C

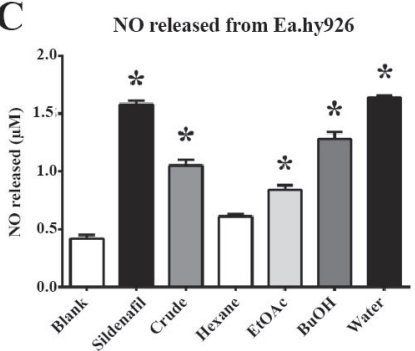

Figure 5. The in vitro effect of $M$. pruriens fractions on the Ea.hy926 cell line. (A) eNOS gene expression, (B) iNOS gene expression, (C) released NO level.

Note: The statistical significance of the differences between groups was determined using one-way ANOVA test. Statistical significance is assumed at $P<0.05$; * when compared to the control group, and \# when compared to Sildenafil-treated group.

As expected, Sildenafil displayed the potential to maintain the intracellular cGMP levels in HCT-15 cells (Figure 6C). Sildenafil acted as an inhibitor that consequently promoted PDE5 gene expression (Figure 6A). Moreover, Sildenafil substantially affected the upregulation of the iNOS gene in HCT-15 cells (Figure 6B). The crude extract of $M$. pruriens seeds significantly retained the intracellular cGMP level, but its efficacy was not equivalent to that of Sildenafil (Figure 6C). The effect of the M. pruriens fractions on restored intracellular cGMP levels was associated with the polarity of the fractions. However, only the $\mathrm{BuOH}$ and water fractions were found to potentially upregulate PDE5 gene expression (Figure 6A), with no significant difference between them. These two fractions significantly induced iNOS gene expression in HCT-15 cells. The water fraction of the M. pruriens seed extract partially elevated the production of NO from HCT-15 cells compared to $\mathrm{BuOH}$ and Sildenafil. Hydrophobic fractions of $M$. pruriens did not affect gene expression or cGMP levels in HCT-15 cells.

A

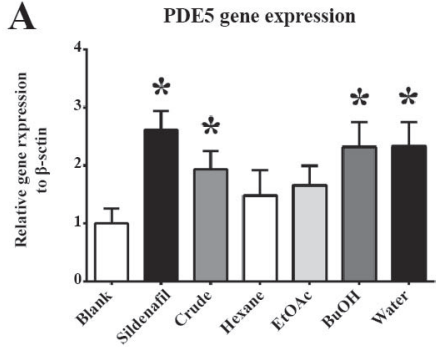

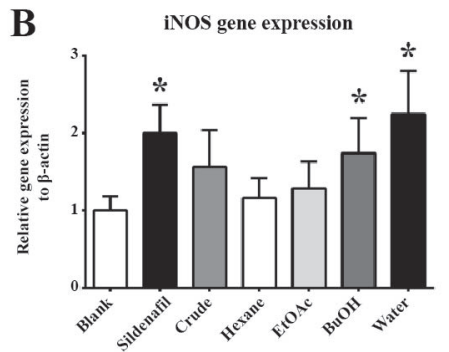

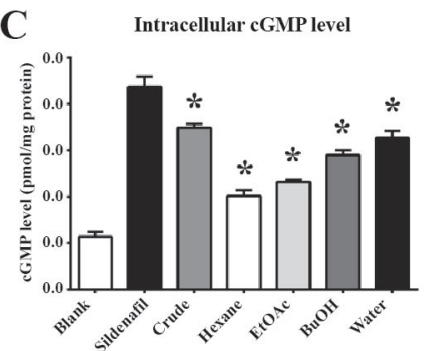

Figure 6. The in vitro effect of $M$. pruriens fractions on HCT-15 cells: (A) PDE5 gene expression, (B) iNOS gene expression, (C) intracellular cGMP level.

Note: The statistical significance of the differences between groups was determined using one-way ANOVA test. Statistical significance is assumed at $P<0.05$; * when compared to the control group, and \# when compared to the Sildenafil-treated group. 


\section{DISCUSSION}

NO is an important molecule in both physiological and pathological functions, including penile erections (Lundberg et al., 2008). In penile erections, NO is produced by two cell types: neuron cells, in which nNOS triggers penile erection, and vascular endothelial cells, in which eNOS plays a role in maintaining penile erection (Forstermann and Sessa, 2011). NO penetrates into target cells, including endothelial cells and smooth muscle cells, and activates soluble guanilyl cyclase (sGC), which stimulates the synthesis of intracellular cGMP from GTP within target cells, leading to smooth muscle relaxation. This cellular mechanism is balanced through the function of the PDE5 enzyme, which is specific to cGMP (Toda et al., 2005). Therefore, NO levels of the target organs; the activity of nNOS, eNOS, and/or sGC in the target cells; and restoration of intracellular cGMP and PDE5 enzyme inhibition are possible therapeutic targets for erectile dysfunction therapy (Williams and Melman, 2012). Although most physicians prefer inhibiting PDE5, incremental measurements of NO production and related NOS enzyme activity is an alternative therapeutic target for ED therapy. A number of natural products, include quercetin, resveratrol, and other phenolic compounds, have been reported to help treat ED via the upregulation of the eNOS gene (Baur and Sinclair, 2006; Schmitt and Dirsch, 2009; Zhang et al., 2015). Sildenafil has also been reported to elevate the expression of the eNOS gene in an in vitro study (Mammi et al., 2011). This information supports activating or upregulating the eNOS gene in ED therapy.

Mucuna pruriens seed extract has been reported to be effective in improving sexual behavior in animal models (Suresh et al., 2009; Ketkar et al., 2011; Suresh and Prakash, 2012). However, the active compounds and their mechanisms of action are unclear. We collected $M$. pruriens seeds from plants cultivated in Mae Taeng District, Chiang Mai Province and obtained extracts using the polarity gradient extraction method to determine the active ingredients by polarity.

Our results showed that the derived substances were not likely to provide antioxidant properties to the M. pruriens extract. The only hydrophobic substance we found was $\gamma$-sitosterol [10], in the $\mathrm{BuOH}$ and water fractions only. Yoshida and Niki (2003) reported on the antioxidant activity of this phytosterol. Surprisingly, L-DOPA, which has been obtained from M. pruriens using polar solvents, such as water and ethanol (Ketkar et al., 2011), was not detected in any of the fractions of $M$. pruriens in our study; we confirmed this by comparing our results with the GC/MS results from an L-DOPA standard. This finding indicated that there might be phytochemical variations between the cultivar used in this study and those used in previous studies.

The differences that exist among the fractions can be clarified by the polar substances at peaks displayed in the front region of the GC chromatogram. 7,9-Di-tert-butyl-1-oxaspiro $(4,5)$ deca-6,9-diene-2,8-dione [5], which was distributed in all of the M. pruriens fractions in our study, is also found in other plants with antioxidant properties (Sharif et al., 2015). Diethyl phthalate [3] was clearly found in the indicated region of the hexane and EtOAC fractions. Protocatechuic acid, methyl ester [4] was found in small amounts in the $\mathrm{BuOH}$ and the water fractions. This protocatechuic acid derivative has been reported to be a potent antioxidant (Kakkar and Bais, 2014), which could, even in small quantities, provide antioxidant activity to the $\mathrm{BuOH}$ and water fractions. Sucrose [1] preferred the hydrophilic fraction, and was thus 
found in small amounts in the $\mathrm{BuOH}$ fraction and was obviously found in the water fraction. Interestingly, 2,4-bis(1,1-dimethylethyl)-phenol [2] was found only in the water fraction. 2,4-bis(1,1-dimethylethyl)-phenol has been found in other plant seeds and has been reported to possess potent antioxidant properties (Kusch et al., 2011). This phenolic substance might provide potent antioxidant activity to the water fraction and overpower other fractions. As few studies have fully investigated 2,4-bis(1,1-dimethylethyl)-phenol, it is of significant interest to investigate the exact chemical structure of these compounds to identify the substances and to measure their specific biological activities.

We examined the effects of the $M$. pruriens seed extracts on three cell lines of interest over a 24-hour period in order to represent, in vitro, the acute effect of these substances on the cells. The MTT results showed that all cell lines survived after being treated with appropriate concentrations $(50 \mu \mathrm{g} / \mathrm{ml})$ of $M$. pruriens seed extracts for 24 hours. These results ensured the non-toxicity of the tested extracts during the observation period.

From the in vitro results, we suggested that the major action of Sildenafil was to inhibit the PDE5 enzyme and to restore intracellular cGMP levels. Its action as a PDE5 inhibitor subsequently elevated PDE5 gene expression in HCT-15, which responded to a high level of cGMP. Sildenafil might also enhance NO production through the upregulation of the eNOS gene in Ea.hy926 cells, which subsequently increase cGMP production and the upregulation of the PDE5 gene. Although Sildenafil stimulated NO production in C6 cells, this effect might be more involved with iNOS gene expression than with the nNOS gene.

The highly polar $M$. pruriens fractions increased NO production in C6 cells. The water fraction displayed significant NO stimulation; this was clearly an effect of stimulating the nNOS gene. According to the GC/MS result, this might be due to 2,4-bis(1,1-dimethylethyl)phenol [2], which was found only in the water fraction. The ability of the water fraction to upregulate nNOS gene expression in C6 cells was promising, as its effect was stronger than sildenafil. iNOS gene expression gradually increased when treatment was applied with higher polar fractions. This result suggested that the substances found in the high polar fractions, including sucrose [1], protocatechuic acid, methyl ester [4], and $\gamma$-sitosterol [10] might be involved in the effect on the iNOS gene.

The same tendency was also found in Ea.hy926, in which the fractions with high polarity promoted NO production. Phytochemicals within the high polar fractions, sucrose [1], protocatechuic acid, methyl ester [4], and $\gamma$-sitosterol [10], might stimulate eNOS gene expression. Diethyl phthalate [3], which was found in the hexane and $\mathrm{BuOH}$ fractions, might be involved with this effect, but a large quantity of this substance was needed to stimulate the expression. This result was similar to the effect of polyphenols, which has been previously reported to stimulate the expression of the eNOS gene (Greselea et al., 2011). We suggested that protocatechuic acid, methyl ester [4] might be involved with eNOS gene expression, as the response of the eNOS gene was correlated to the amount of this substance found in the $\mathrm{BuOH}$ and water fractions. iNOS gene expression was considerably elevated when treated with the water fraction, which indicated the effect of 2,4-bis(1,1-dimethylethyl)-phenol [2] on the iNOS gene in endothelial cells.

In HCT-15 cells, all M. pruriens seed fractions significantly maintained the intracellular cGMP level, although Sildenafil's effect was significantly stronger. This result showed that M. pruriens seed fractions stimulated the HCT-15 cells. Although the results demonstrated a correspondence of PDE gene expression between the Sildenafil-treated and water fraction- 
treated groups, further investigation of the effect of the $M$. pruriens fraction on PDE5 activity is required to fully explain its effect. The effect of the $M$. pruriens fractions might be due to the upregulation of the iNOS gene that consequently promoted NO production and cGMP synthesis (Vanini et al., 2015). This upregulation of iNOS might be the effect of hydrophilic compounds in the $M$. pruriens extract, especially 2,4-bis(1,1-dimethylethyl)-phenol. This finding indicated that $M$. pruriens seeds could stimulate the expression of NOS genes, especially nNOS, which has been found to diminish in ED (Dashwood et al., 2016). This study has shown that such an effect might involve the presence of 2,4-bis(1,1-dimethylethyl)phenol [2].

Taken together, our results indicated that the active, beneficial ingredients present in M. pruriens seeds for treating erectile dysfunction might be the polar components that have the capability to stimulate NO production in both endothelial and neuron cells through the upregulation of NOS genes.

This study had some limitations. We only identified the phytochemicals using the NIST library database, which may have led to inaccuracies. The in vitro model was only tested for 24 hours, which was not long enough to determine the long-term effects or toxicity of each fraction. In addition, our study was in vitro only; further study of animal models are required to ensure the potency of the M. pruriens fraction in living creatures.

To address these limiations, all active compounds found in the $M$. pruriens seeds extracts, especially in the water fraction, should be verified using further advanced identification techniques, such as nuclear magnetic resonance spectroscopy (NMR) or X-ray crystallography. Furthermore, prolonged in vitro experiments and in vivo studies of $M$. pruriens seed extracts should be conducted to confirm the effectiveness and toxicity of these natural compounds before considering their use in humans.

\section{CONCLUSION}

Of the active compounds in, the hydrophilic substances offered the most likely potential to effectively treat ED. These included protocatechuic acid, methy ester, $\gamma$-sitosterol, and especially 2,4-bis(1,1-dimethylethyl)-phenol; these were present in the water fraction of the $M$. pruriens extract obtained from the polarity gradient extraction process. These active compounds displayed potent antioxidant activity and increased NO production in neurons and endothelial cells in vitro and were likely involved with the upregulation of NOS gene expression. The water fraction of the M. pruriens seed extract was more powerful than the positive control, Sildenafil, at upregulating the expression of the nNOS gene in neurons, showing its promise as a natural product for treating erectile dysfunction.

\section{ACKNOWLEDGEMENTS}

The Thailand Excellence Center of Tissue Engineering and Stem Cells, Faculty of Medicine, Chiang Mai University supported this research. We also thank the Graduate School, Chiang Mai University, for providing academic and documentation support and the $1^{\text {st }}$ Regional Medical Sciences Center, Chiang Mai for use of the GC/MS instrument. 


\section{REFERENCES}

Adebowale, Y.A., Adeyemi, A., and Oshodi, A.A. 2005. Variability in the physicochemical, nutritional and antinutritional attributes of six Mucuna species. Food Chemistry. 89: 37-48. https://doi.org/10.1016/j.foodchem.2004.01.084

Andersson, K.E. 2011. Mechanisms of penile erection and basis for pharmacological treatment of erectile dysfunction. Pharmacological Reviews. 63: 811-859. https://doi. org/10.1124/pr.111.004515

Baur, J.A., and Sinclair, D.A. 2006. Therapeutic potential of resveratrol: the in vivo evidence. Nature Review: Drug Discovery. 5: 493-506. https://doi.org/10.1038/nrd2060

Both, S., Everaerd, W., Laan, E., and Gooren, L. 2005. Effect of a single dose of levodopa on sexual response in men and women. Neuropsychopharmacology. 30: 173-183. https:// doi.org/10.1038/sj.npp.1300580

Bryan, N.S., and Grisham, M.B. 2007. Methods to detect nitric oxide and its metabolites in biological samples. Free Radical Biology and Medicine. 43(5): 645-657. https://doi. org/10.1016/j.freeradbiomed.2007.04.026

Burnett, A.L. 2002. Nitric oxide regulation of penile erection: biology and therapeutic implications. Journal of Andrology. 23(5): S20-S26. https://doi.org/10.1002/j.19394640.2002.tb02292.x

Chamsi-Pasha, H. 2001. Sildenafil (Viagra) and the heart. Journal of Family and Community Medicine. 8(2): 63-66.

Dashwood, M.R., Crump, A., Shi-Wen, X., and Loesch, A. 2016. Identification of neuronal Nitric Oxide Synthase (nNOS) in human penis: a potential role of reduced neuronallyderived nitric oxide in erectile dysfunction. Current Pharmaceutical Biotechnology. 12(9): 1316 -1321. https://doi.org/10.2174/138920111798280965

Dean, R.C., and Lue, T.F. 2005. Physiology of penile erection and pathophysiology of erectile dysfunction. The Urologic Clinics of North America. 32(4): 379-395. https://doi.org/ 10.1016/j.ucl.2005.08.007

Forstermann, U., and Sessa, W.C. 2011. Nitric oxide synthases: regulation and function. European Heart Journal. 33(7): 837a-837d. https://doi.org/10.1093/eurheartj/ehr304

Gratzke, C., Angulo, J., Chitaley, K., Dai, Y.T., Kim, N.N., Paick, J.S., Simonsen U., Ückert, S., Wespes, E., Andersson, K.E., et al. 2010. Anatomy, physiology, and pathophysiology of erectile dysfunction. Journal of Sexual Medicine. 7(1 pt 2): 445-475. https://doi.org/ 10.1111/j.1743-6109.2009.01624.x

Greselea, P., Cerlettib, C., Guglielminia, G., Pignatellic, P., Gaetanob, G., and Violic, F. 2011. Effects of resveratrol and other wine polyphenols on vascular function: an update. Journal of Nutritional Biochemistry. 22: 201-211. https://doi.org/10.1016/j. jnutbio.2010.07.004

Jing, P., Zhao, S.J., Jian, W.J., Qian, B.J., Dong, Y., and Pang, J. 2012. Quantitative studies on structure-DPPH• scavenging activity relationships of food phenolic acids. Molecules. 17: 12910-12924. https://doi.org/10.3390/molecules171112910

Kakkar, S., and Bais, S. 2014. A review on protocatechuic acid and its pharmacological potential. International Scholarly Research Notices: Pharmacology. 952943. https:// doi.org/10.1155/2014/952943 
Karunanithi, M., Raj, C.D., Jegadeesan, M., and Kavimani, S. 2012. Comparative GCMS analysis and in vitro screening of four species of mucuna. Asian Journal of Pharmaceutical and Clinical Research. 5(4): 239-243.

Kavitha, C., and Thangamani, C. 2014. Amazing bean "Mucuna pruriens": A comprehensive review. Journal of Medicinal Plants Research. 8(2): 138-143. https://doi.org/10.5897/ JMPR2013.5036

Ketkar, S., Gopu, C.L., Badgujar, L., Paradkar, A., and Mahadik, K. 2011. Male sexual behaviour improving effect of lipid based extract of Mucuna pruriens in rats. Pharmacologyonline. 1: 1-14.

Kusch, P., Deininger, S., Specht, S., Maniako, R., Haubrich, S., Pommerening, T., Lin, P.K., Hoerauf, A., and Kaiser, A. 2011. In vitro and In vivo antimalarial activity assays of seeds from Balanites aegyptiaca: compounds of the extract show growth inhibition and activity against plasmodial aminopeptidase. Journal of Parasitology Research. 368692. https://doi.org/10.1155/2011/368692

Lundberg, J.O., Weitzberg, E., and Gladwin, M.T. 2008. The nitrate-nitrite-nitric oxide pathway in physiology and therapeutics. Nature Review: Drug Discovery. 7: 156-167. https://doi.org/10.1038/nrd2466

Majekodunmi, S.O., Oyagbemi, A.A., Umukoro, S., and Odeku, O.A. 2011. Evaluation of the anti-diabetic properties of Mucuna pruriens seed extract. Asian Pacific Journal of Tropical Medicine. 4(8): 632-636. https://doi.org/10.1016/S1995-7645(11)60161-2

Mammi, C., Pastore, D., Lombardo, M.F., Ferrelli, F., Caprio, M., Consoli, C., Tesauro M., Gatta L., Fini M., Federici M., et al. 2011. Sildenafil reduces insulin-resistance in human endothelial cells. PLoS ONE. 6(1): e14542. https://doi.org/10.1371/journal. pone. 0014542

Mei, X.L., Yang, Y., Zhang, Y.J., Li, Y., Zhao, J.M., Qiu, J.G., Zhang, W.J., Jiang, Q.W., Xue, Y.Q., Zheng, D.W., et al. 2015. Sildenafil inhibits the growth of human colorectal cancer in vitro and in vivo. American Journal of Cancer Research. 5(11): 3311-3324.

NIH. 1993. Consensus development conference statement. Impotence. December 7-9, 1992. International Journal of Impotence Research. 5(4): 181-284.

Prins, J., Blanker, M.H., Bohnen, A.M., Thomas, S., and Bosch, J.L.H.R. 2002. Prevalence of erectile dysfunction: a systematic review of population-based studies. Internation Journal of Impotence Research. 14(6): 422-432. https://doi.org/10.1038/sj.ijir.3900905

Pulikkalpura, H., Kurup, R., Mathew, P.J., and Baby, S. 2015. Levodopa in Mucuna pruriens and its degradation. Scientific Reports. 5(11078). https://doi.org/10.1038/srep11078

Sasidharan, S., Chen, Y., Saravanan, D., Sundram, K.M., and Latha, L.Y. 2011. Extraction, isolation and characterization of bioactive compounds from plants extracts. African Journal of Traditional Complementary and Alternative Medicines. 8(1): 1-10.

Schefe, J.H., Lehmann, K.E., Buschmann, I.R., Unger, T., and Funke-Kaiser, H. 2006. Quantitative real-time RT-PCR data analysis: current concepts and the novel "gene expression's CT difference" formula. Journal of Molecular Medicine. 84(11): 901-10. https://doi.org/10.1007/s00109-006-0097-6

Schmitt, C.A., and Dirsch, V.M. 2009. Modulation of endothelial nitric oxide by plant-derived products. Nitric Oxide. 21: 77-91. https://doi.org/10.1016/j.niox.2009.05.006 
Sharif, H.B., Mukhtar, M.D., Mustapha, Y., and Lawal, A.O. 2015. Preliminary investigation of bioactive compounds and bioautographic studies of whole plant extract of Euphorbia pulcherrima on Escherichia coli, Staphylococcus aureus, Salmonella typhi, and Pseudomonas aeruginosa. Advances in Pharmaceutics. 485469. https://doi. org/10.1155/2015/485469

Suresh, S., and Prakash, S. 2012. Effect of Mucuna pruriens (Linn.) on sexual behavior and sperm parameters in streptozotocin-induced diabetic male rat. Journal of Sexual Medicine. 9: 3066-3078. https://doi.org/10.1111/j.1743-6109.2010.01831.x

Suresh, S., Prithiviraj, E., and Prakash, S. 2009. Dose- and time-dependent effects of ethanolic extract of Mucuna pruriens Linn. seed on sexual behaviour of normal male rats. Journal of Ethnopharmacology. 122: 497-501. https://doi.org/10.1016/j.jep.2009.01.032

Toda, N., Ayajiki, K., and Okamura, T. 2005. Nitric oxide and penile erectile function. Pharmacology \& Therapeutics. 106: 233-266. https://doi.org/10.1016/j.pharmthera. 2004.11.011

Vanini, F., Kashfi, K., and Nath, N. 2015. The dual role of iNOS in cancer. Redox Biology. 6: 334-343. https://doi.org/10.1016/j.redox.2015.08.009

Williams, S.K., and Melman, A. 2012. Novel therapeutic targets for erectile dysfunction. Maturitas. 71: 20-27. https://doi.org/10.1016/j.maturitas.2011.11.004

Yoshida, Y., and Niki, E. 2003. Antioxidant effects of phytosterol and its components. Journal of Nutritional Science and Vitaminology. 49(4): 277-280.

Zhang, Y., Huang, C., Liu, S., Bai, J., Fan, X., Guo, J., Jia, Y., Zhang, Z., Chen, X., Jia, Y., et al. 2015. Effects of quercetin on intracavernous pressure and expression of nitrogen synthase isoforms in arterial erectile dysfunction rat model. International Journal of Clinical and Experimental Medicine. 8(5): 7599-7605. 